\title{
Surfaces with Controllable Topography and Chemistry Used as a Template for Protein Crystallization
}

\author{
Wester de Poel,*(1) Joris A. W. Münninghoff,* Johannes A. A. W. Elemans,* Willem J. P. van Enckevort, *(1) \\ Alan E. Rowan,* and Elias Vlieg*(0)
}

Radboud University, Institute for Molecules and Materials, Heyendaalseweg 135, Nijmegen, 6525 AJ, The Netherlands

\section{Supporting Information}

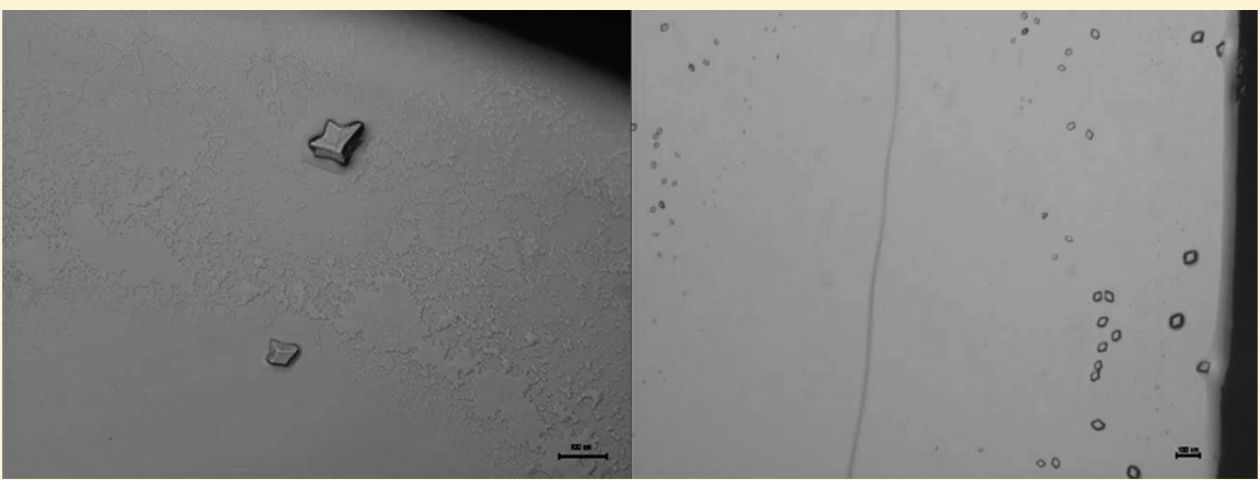

ABSTRACT: Surfaces with controllable topography and chemistry were prepared to act as substrates for protein crystallization, in order to investigate the influence of these surface properties on the protein crystallization outcome. Three different methods were investigated to deposit 1,3,5-tris(10-carboxydecyloxy)benzene (TCDB) on a muscovite mica substrate to find the best route for controlled topography. Of these three, sublimation worked best. Contact angle measurements revealed that the surfaces with short exposure to the TCDB vapor (20 min or less) are hydrophilic, while surfaces exposed for 30 min or longer are hydrophobic. The hydrophilic surfaces are flat with low steps, while the hydrophobic surfaces contain macrosteps. Four model proteins were used for crystallization on the surfaces with controlled topography and chemistry. Hen egg white lysozyme crystals were less numerous on the surface with macrosteps than on smoother surfaces. On the other hand, insulin nucleated faster on the hydrophobic surfaces with macrosteps, and therefore, the crystals were more abundant and smaller. Bovine serum albumin and talin protein crystals were more numerous on all TCDB functionalized surfaces, compared to the reference clean muscovite mica surfaces. Overall, this shows that surface topography and chemistry is an important factor that partly determines the outcome in a protein crystallization experiment.

\section{INTRODUCTION}

Self-assembled monolayers (SAMs) have been shown to be able to direct $2 \mathrm{D}$ crystallization, ${ }^{1}$ as well as $3 \mathrm{D}$ crystallization ${ }^{2}$ in terms of chirality, ${ }^{3,4}$ polymorphism, ${ }^{5,6}$ or epitaxial crystal growth. ${ }^{7,8}$ For this purpose SAMs need to be stable under the applied crystallization conditions, and for this reason monolayers are usually used that are covalently bound to the substrate, for example the combination of organothiol molecules on gold. ${ }^{2-}$

Factors that have been reported to be important in the crystal growth of biological macromolecules on a substrate are surface chemistry, ${ }^{9-15}$ surface topography, ${ }^{16}$ and a match of the lattice parameters of the substrate and the macromolecule, which, under certain conditions, can introduce epitaxial crystal growth. ${ }^{17,18}$ Surface topography can influence nucleation behavior by increasing the contact area for the molecules. The extent of this influence can be affected by the surface chemistry and related chemical interactions between the crystallizing compound and the substrate. Several protein crystallization agents have received attention, such as bioglass and porous materials, ${ }^{19,20}$ with the aim of providing insight into the crystallization process and improving protein crystallization. In this context, Liu et al. ${ }^{16}$ investigated the influence of surface roughness on the crystallization of hen egg white lysozyme (HEWL). They varied the chemical functionality of the glass surfaces by depositing different polymers on the surface. The surface roughness was measured using atomic force microscopy (AFM) and seemed to be poorly defined or controlled, as a larger scanning range gave a different value for the surface roughness. Therefore, we aim to control the surface topography, without changing the molecular constituents on the surface, in order to keep the chemical functionality constant, to exclusively investigate the effect of surface roughness and morphology on the crystallization of various proteins. In this

Received: August 22, 2017

Revised: November 17, 2017

Published: January 9, 2018 


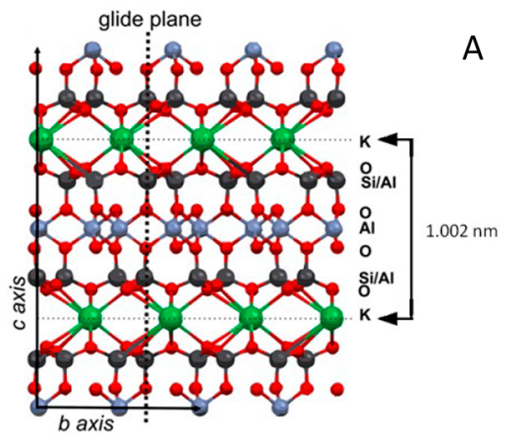

A

B

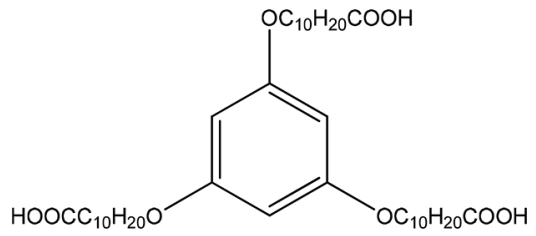

Figure 1. Ball and stick model of muscovite mica (A), and chemical structure of 1,3,5-tris(10-carboxydecyloxy)benzene (TCDB) (B).
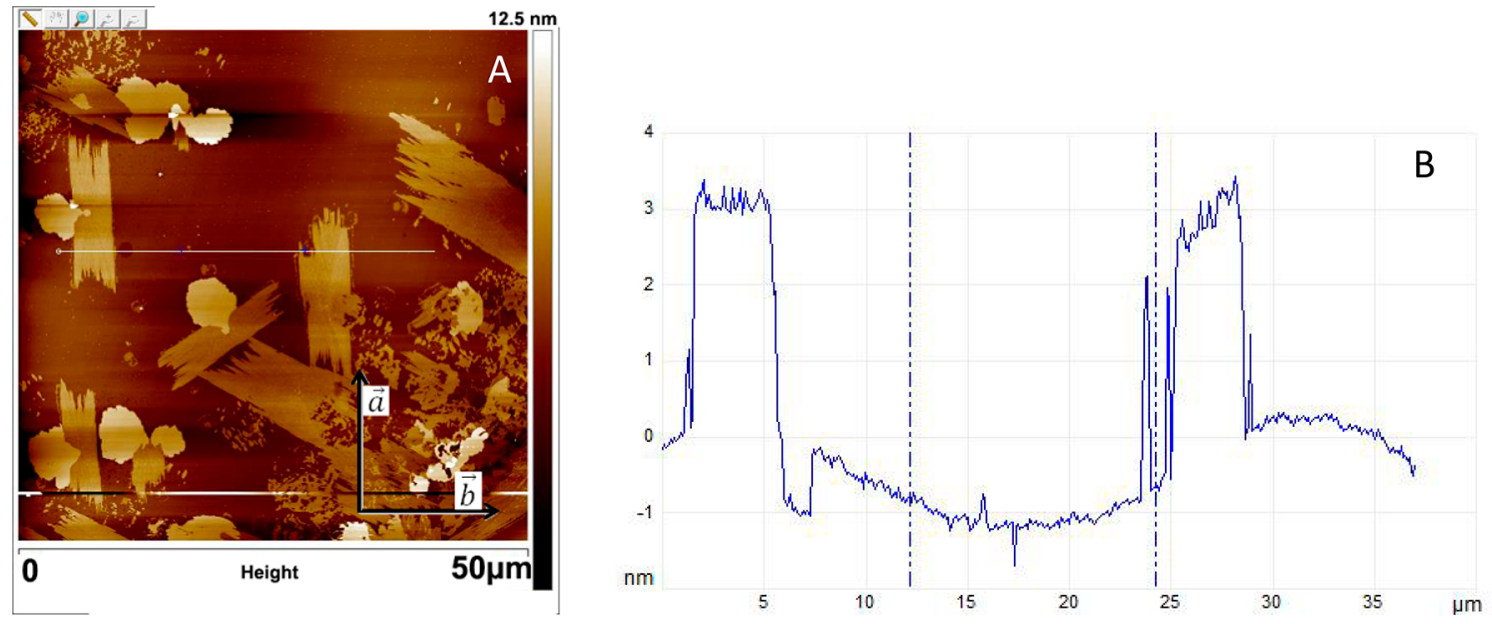

Figure 2. AFM height image of drop casted TCDB structures on muscovite mica (A); cross section of the surface (B).

way we hope to create a surface with the ideal properties for protein crystallization.

Muscovite mica (Figure 1A) can be used as a suitable substrate to build surfaces with controllable topography, as this crystal is atomically flat after cleaving. ${ }^{21}$ A suitable molecule is subsequently needed to introduce features on the muscovite mica surface with a controlled topography. Using the same molecule for each experiment increases the likelihood that the chemical functionality is controlled.

Several examples exist of molecular layers grown on muscovite mica. For example, alkylsilanes can be self-assembled on the muscovite mica (001) surface and can be covalently attached by a hydrolysis reaction. ${ }^{22-26}$ Other compounds that have been used to form self-assembled monolayers are octadecylphosphonic acid, ${ }^{27}$ octadecylamine, ${ }^{28}$ and heptopus, ${ }^{29}$ all of which contain a hydrophilic chemical entity and hydrophobic tails, and the hydrophilic part of which is oriented toward the polar muscovite mica surface. Crown-ethers have been shown to grow on the muscovite mica surface by binding to the surface ions. ${ }^{30}$ Parahexaphenyl is the only example, so far, that has been found to grow in epitaxial layers along the [110] direction on top of the (001) face of muscovite mica. ${ }^{31,32}$ Of these examples only the latter seems potentially useful to create multilayered rough structures that are stable under protein crystallization conditions. However, we have found a better alternative that is easy to evaporate onto the muscovite mica surface, which remains on the surface when placed in water, and provides surfaces with variable topography.

This alternative is 1,3,5-tris(10-carboxydecyloxy) benzene (TCDB, Figure 1B), and was used to grow molecular (multi)layers onto the muscovite (001) surface to obtain surfaces with variable topography and chemistry. TCDB was selected for several reasons; the solubility in water is poor, it can be evaporated at low temperatures and forms well-defined layers on the muscovite mica surface. TCDB was evaporated, dip coated and drop casted onto the muscovite mica surface, to find the optimal deposition technique. The resulting surfaces were analyzed using AFM. The surface roughness, topography, and chemistry can be controlled depending on the method and the variations in deposition time. The functionalized surfaces were subsequently used to crystallize four model proteins in a hanging drop configuration (hen egg white lysozyme (HEWL), bovine insulin, bovine serum albumin (BSA), and talin). The crystallization was followed over time and compared to the crystallization on clean cleaved muscovite mica in terms of number of crystals, nucleation speed, crystal size, and possible epitaxial crystal growth.

\section{EXPERIMENTAL SECTION}

Muscovite mica (monoclinic, $a=0.51906 \mathrm{~nm}, b=0.9008 \mathrm{~nm}, c=$ $2.0047 \mathrm{~nm}, \beta=95.757^{\circ}$, space group $C 2 / c$, chemical formula $\mathrm{KAl}_{2}\left(\mathrm{Si}_{3} \mathrm{Al}\right) \mathrm{O}_{10}(\mathrm{OH})_{2}$ (quality grade ASTM-V1)) was obtained from S\&J Trading Inc. Glen Oaks NY USA. The synthesis of TCDB can be found in the Supporting Information (SI-1).

Three different approaches were used to apply the TCDB onto the mica surface. In the drop casting experiment $9 \mu \mathrm{L}$ of a $10^{-4} \mathrm{M}$ solution of TCDB in ethanol (absolute, Emsure, ACS, ISO, Reag. Ph. Eur. obtained from Merck) was deposited onto a freshly cleaved muscovite mica surface and left to dry. In the dip-coating experiments, cleaved muscovite mica was submerged into a solution of $10^{-4} \mathrm{M}$ TCDB in ethanol for $10 \mathrm{~s}$, removed from the solution, vertically dried for $20 \mathrm{~s}$, 

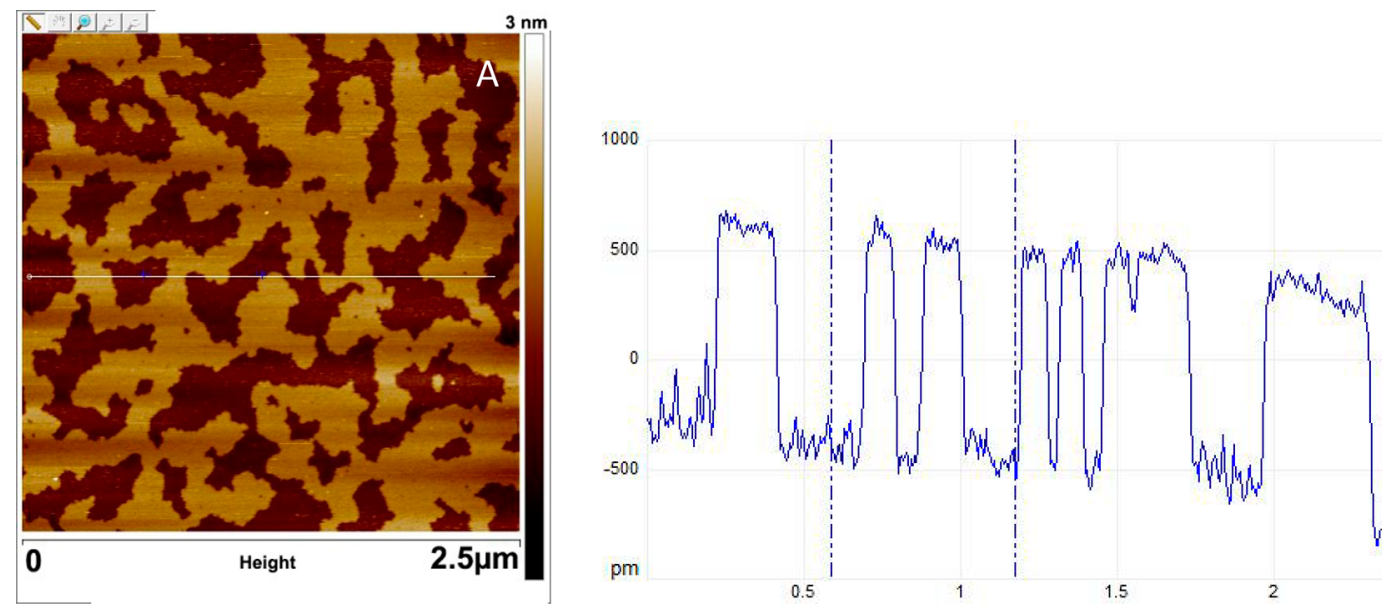

B

Figure 3. AFM height image of dip-coated TCDB on muscovite mica (A); cross section of the surface (B).
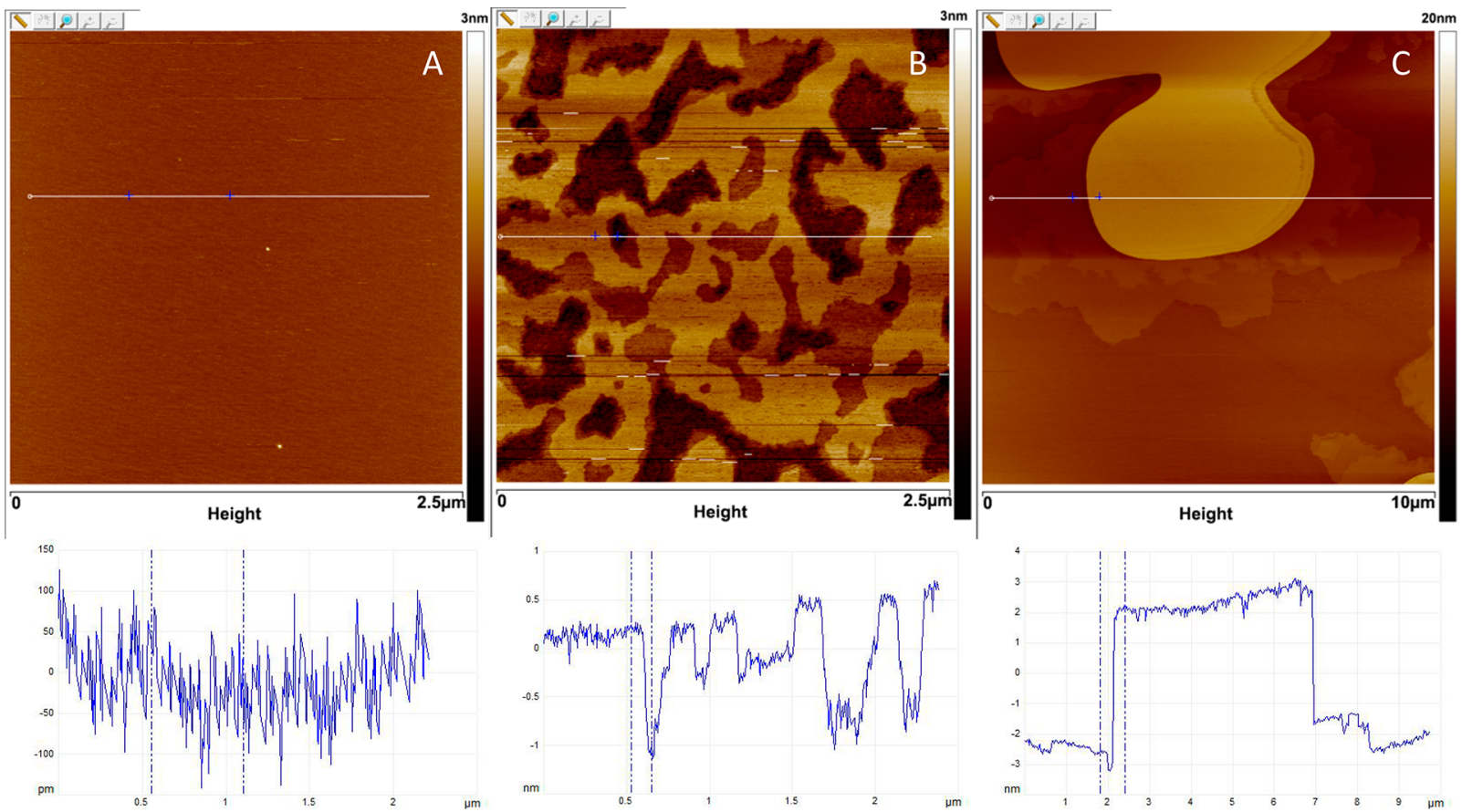

Figure 4. AFM height images of evaporated TCDB on muscovite mica after 6 min showing a flat substrate (A), 20 min showing a surface with low steps (B), and $60 \mathrm{~min}$ of growth showing a surface with macrosteps (C).

and finally horizontally dried for at least an hour under a gentle nitrogen gas flow. The evaporation of TCDB onto the muscovite mica surface was performed by heating TCDB to $100{ }^{\circ} \mathrm{C}$ under a glass beaker with mica facing down toward the TCDB source. For more details see. ${ }^{30}$

AFM measurements were carried out using a Dimension 3100 AFM and a NanoScope Multimode 8 AFM with HA-NC tips from NTMDT. The roughness was calculated with NanoScope analysis software, and using these values obtained from different samples the standard deviation was calculated to give a measure for reproducibility.

Contact angles were measured of a $20 \mu \mathrm{L}$ water droplet placed on a functionalized muscovite mica surface from a microscopic image, viewed from the side, using Image Pro software. At least four different measurements on different samples were performed for every type of surface.

The protein crystallization methods are described in SI-2. The protein crystallization experiments were repeated five times for each type of surface. All experiments were performed on the same day, with the same solutions, and subjected to the same external conditions. The drop of the crystallization mixture comprises a mica-solution contact surface area of approximately $10 \mathrm{~mm}^{2}$. Only crystals in contact with the muscovite mica in this contact area were counted. The crystals were counted manually (in situ) with the help of optical microscopy. The crystallographic orientation of muscovite mica was determined using X-ray diffraction and optical polarization microscopy in conoscopy mode.

\section{RESULTS AND DISCUSSION}

Surface Preparation. Drop casting TCDB on the muscovite surface, followed by evaporation of the solvent, gives rise to several different features of (multi)layers of TCDB with variable height, depicted in Figure 2. As can be inferred from the cross section of Figure 2A, shown in Figure 2B, a nearly full TCDB layer of approximately $0.8 \pm 0.2 \mathrm{~nm}$ in height was obtained, which probably corresponds with a monolayer. On top of this layer some elongated structures are visible that have grown in the crystallographic a-direction of muscovite mica and have well-defined edges parallel to this direction. The 
edge free energy is low in the perpendicular direction, leading to morphological instability and less well-defined edges. The height of the layers $(3 \mathrm{~nm})$ indicates that the molecules in the layer do not lie flat, or that the layer consists of more than one molecule. The structures are found with angles of $60^{\circ}$ with respect to each other, as a consequence of the pseudohexagonal symmetry of the underlying muscovite mica surface. This illustrates that there is an epitaxial relationship between the muscovite mica and TCDB, which could propagate into ensuing higher layers. Epitaxy, and domains of TCDB were also observed on graphite by $\mathrm{Lu}$ et al. ${ }^{33}$ with ECSTM measurements at the solid-liquid interface.

Compared to the drop casting experiments, TCDB layers that were produced using dip-coating provided smooth layers with fewer features and no anisotropy (Figure 3). The nonclosed layer depicted in Figure $3 \mathrm{~A}$ is $1.0 \pm 0.2 \mathrm{~nm}$ high, which would correspond with the first layer depicted in Figure 2. Closed layers are also observed using the dip-coating technique. Dewetting phenomena will determine the surface morphology to a large extent in the cases of drop-casting and dip-coating. $^{34}$

Evaporation of TCDB was also investigated, because of the poor homogeneity, reproducibility, and control of surface features for the drop-casted and dip-coated surfaces. Different growth periods of $6,20,30,40,50$, and $60 \mathrm{~min}$ (Figure 4) were investigated. Molecularly smooth planar terraced surfaces were obtained for every growth interval. A flat surface remains after 6 min of growth (Figure 4A), after $20 \mathrm{~min}$ of growth a multilayered structure emerges (Figure 4B). The layers depicted in Figure $4 \mathrm{~B}$ show heights of $0.6 \pm 0.2 \mathrm{~nm}$, which indicates that single molecular layers are present. After $30 \mathrm{~min}$ of growth or more, higher multilayered structures emerge with heights of several nanometres (Figure 4C). The height of each of these features varies from sample to sample. This shows that the layer-by-layer growth goes on until the supply of TCDB ceases. Underneath the highest feature in Figure 4C, two layers can be observed with a height that corresponds to a single molecule $(0.8 \pm 0.3 \mathrm{~nm})$. The different surface morphologies show no obvious epitaxial orientation, but there is a clear layerby-layer growth. No in-plane ordering can be established from the AFM experiments, but the molecularly smooth terraces do infer molecular order in the out-of-plane direction.

The AFM measurements of these surfaces were analyzed for their roughness $\left(\mathrm{R}_{\mathrm{rms}}\right)$. At least eight different locations of 2.5 by $2.5 \mu \mathrm{m}$ were measured on 3 different samples for every condition. The variation in roughness between these spots and samples is expressed as the standard deviation (Table 1), and it shows a high degree of reproducibility. The roughness of the layer after $6 \mathrm{~min}$ of growth is close to the noise level of the AFM (i.e., $0.2 \mathrm{~nm}$ ), and it could signify that a complete TCDB layer has formed (Figure 4A). The possibility that the surface is still empty can be excluded because of the different protein crystal growth behavior with respect to clean muscovite mica (vide infra). After $20 \mathrm{~min}$ of growth a multilayered structure with low surface roughness is observed (Figure 4B), and after longer growth times even higher planar features with macrosteps are observed, leading to a high surface roughness (Figure 4C). The TCDB macrosteps are present on all surfaces that have been exposed to TCDB vapor for $30 \mathrm{~min}$ or more.

The contact angles of a water droplet on the functionalized surfaces were measured to obtain information about the surface chemistry (Table 1). The measured contact angles indicate that the surfaces where TCDB was evaporated for $30 \mathrm{~min}$ or longer
Table 1. Roughness Values ( $\mathrm{R}_{\mathrm{rms}}$ in $\mathrm{nm}$ ) of TCDB Layers Grown by Evaporation on Muscovite Mica for Different Growth Times ${ }^{a}$

$\begin{array}{cccc}\begin{array}{c}\text { Growth } \\ \text { time }(\mathrm{min})\end{array} & \begin{array}{c}\text { Roughness } \\ \left(\mathrm{R}_{\mathrm{rms}}(\mathrm{nm})\right)\end{array} & \begin{array}{c}\text { Total of scanned } \\ \text { surface area }\left(\mu \mathrm{m}^{2}\right)\end{array} & \begin{array}{c}\text { Contact angle of } \\ \text { water drop }\end{array} \\ \mathbf{6} & 0.4 \pm 0.05 & 150 & 28^{\circ} \pm 2^{\circ} \\ \mathbf{2 0} & 0.6 \pm 0.04 & 50 & 26^{\circ} \pm 4^{\circ} \\ \mathbf{3 0} & 2.8 \pm 0.06 & 700 & 48^{\circ} \pm 6^{\circ} \\ \mathbf{4 0} & 1.8 \pm 0.1 & 250 & 55^{\circ} \pm 3^{\circ} \\ \mathbf{5 0} & 0.6 \pm 0.05 & 250 & 43^{\circ} \pm 4^{\circ} \\ \mathbf{6 0} & 1.9 \pm 0.1 & 350 & 40^{\circ} \pm 8^{\circ}\end{array}$

${ }^{a}$ Values were calculated from at least 8 AFM measurements of 2.5 by $2.5 \mu \mathrm{m}$ surface areas. Average contact angles of a water droplet on the different functional surfaces of at least 4 measurements on different samples.

are hydrophobic in nature, while those grown for a shorter duration are hydrophilic. This change in surface chemistry may be associated with the change in surface topography as observed with AFM, that is, the transition of the flat surfaces with few surface features (Figure $4 \mathrm{~A}$ and $4 \mathrm{~B}$ ) to the larger features depicted in Figure 4C. The hydrophilic part of the molecule is probably available on the smooth surfaces, while the hydrophobic part is exposed to the surface after more than 20 min of TCDB evaporation.

We conclude that evaporation leads to the most reproducible results and the best control over roughness. This method was therefore selected to produce samples for the subsequent protein crystallization experiments.

Protein Crystallization. The TCDB surfaces which were exposed to growth for 6,20 , and 60 min were selected for protein crystallization, and a reference surface of cleaved muscovite mica was used as well. The evaporated TCDB material is still present on the muscovite mica surface after being submerged in water for 4 days, as observed with AFM. Therefore, it is expected that the layers remain stable during protein crystallization. Both the different surface topography and the associated change in surface chemistry may affect the protein crystallization outcome. The neutral conditions of the BSA and talin protein solutions allow for deprotonation of a carboxylic acid group, which may affect the crystallization if these groups are available at the drop-surface interface. The contact angle experiments indicate that this is likely the case for the TCDB functionalized surfaces that were treated for $20 \mathrm{~min}$ or less.

The number of protein crystals is constant after 3 days for all four investigated proteins. Insulin shows significant differences in nucleation time and crystal size (Figure 5 and 6). TCDBfunctionalized hydrophobic surfaces with the higher surface features (20 and $60 \mathrm{~min}$ of evaporation) show insulin nucleation after 1 day, instead of 2 days for muscovite mica and the TCDB-functionalized hydrophilic surface with the lowest features. The TCDB functionalized hydrophobic surface with the highest features also contains the most crystals, while the largest crystals are obtained on TCDB-functionalized hydrophilic surface with its lower features (20 min of TCDB evaporation). This can be explained by the lower amount of crystals, giving rise to bigger crystals. More crystals form on the hydrophobic surfaces despite the fact that insulin contains a hydrophilic outer shell, meaning that the preferential nucleation is dominated by the surface morphology, i.e. by the presence of the macrosteps. There is also a significant difference in the 


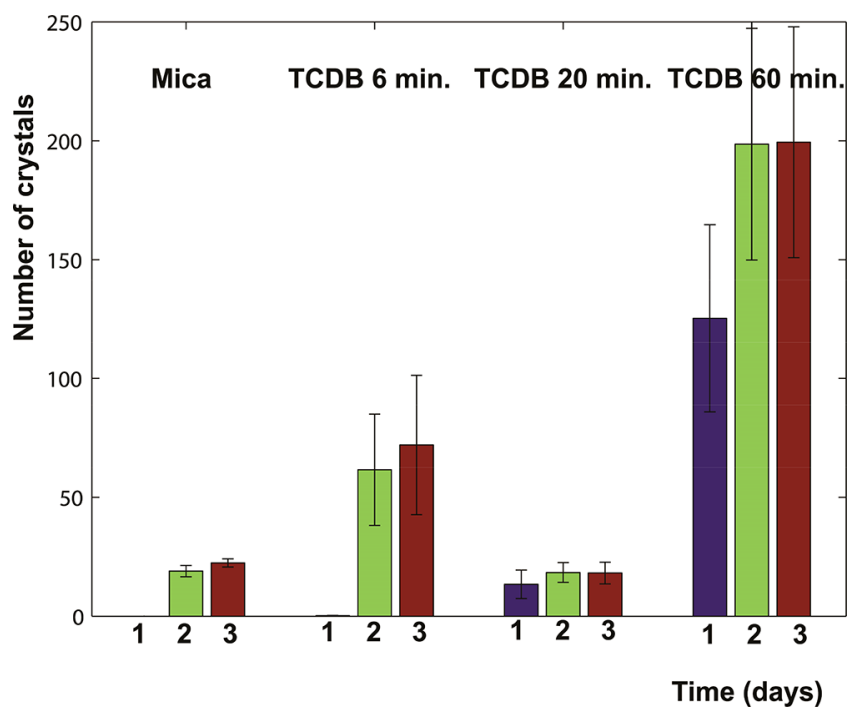

Figure 5. Number of insulin crystals on (functionalized) muscovite mica as a function of time.

amount of insulin crystals between the TCDB-functionalized surface (6 $\mathrm{min}$ of TCDB evaporation) and the reference muscovite mica surface, which points to the presence of a TCDB (mono)layer.

In the case of HEWL, significantly fewer crystals were formed after 3 days on the TCDB-functionalized hydrophobic surfaces with the largest surface features $(60 \mathrm{~min}$ of evaporation), compared to the other TCDB-functionalized surfaces (Figure 7). This finding is in agreement with the results observed by Liu et al., ${ }^{16}$ who observed fewer HEWL crystals on rougher surfaces. HEWL has a hydrophilic surface and prefers to crystallize on the hydrophilic surfaces, therefore, here the surface chemistry is the dominant factor in determining the nucleation behavior. The nucleation time and the size of the HEWL crystals is not influenced by the TCDB-functionalized surfaces.

The greatest number of talin crystals can be found on the TCDB-functionalized surface with $20 \mathrm{~min}$ of TCDB evaporation (Figure 8). However, the number of crystals grown on the reference muscovite mica surface is in all cases less than on the TCDB functionalized surfaces. This indicates that talin has some preference for the surfaces covered by TCDB.

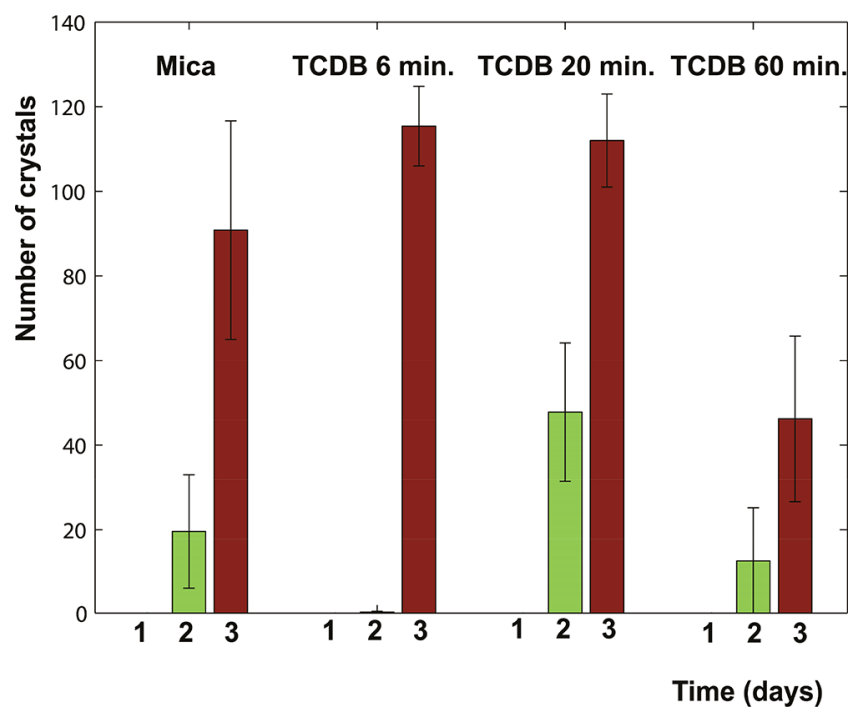

Figure 7. Number of HEWL crystals on (functionalized) muscovite mica as a function of time.

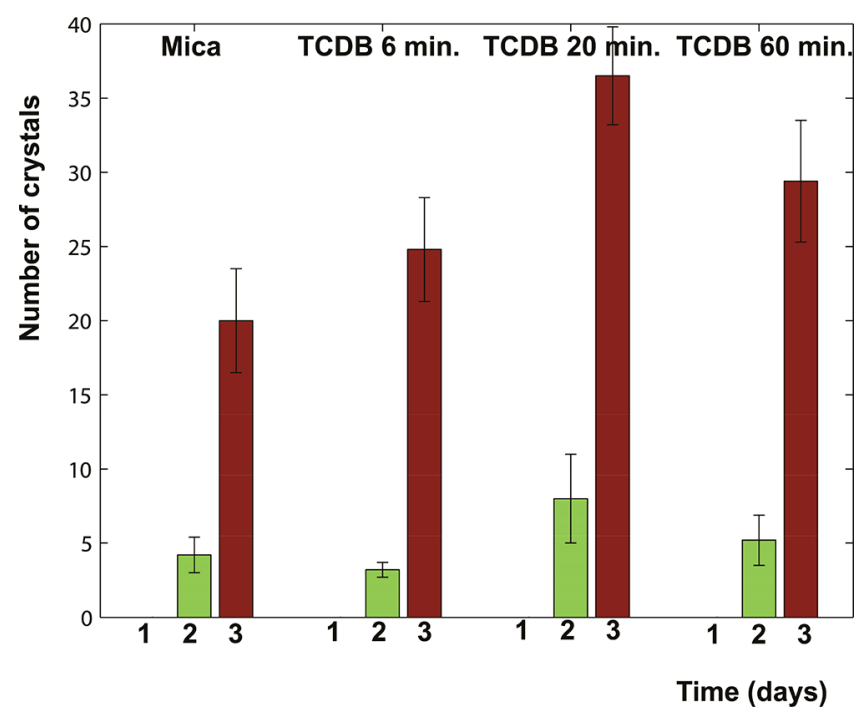

Figure 8. Number of talin crystals on (functionalized) muscovite mica as a function of time.

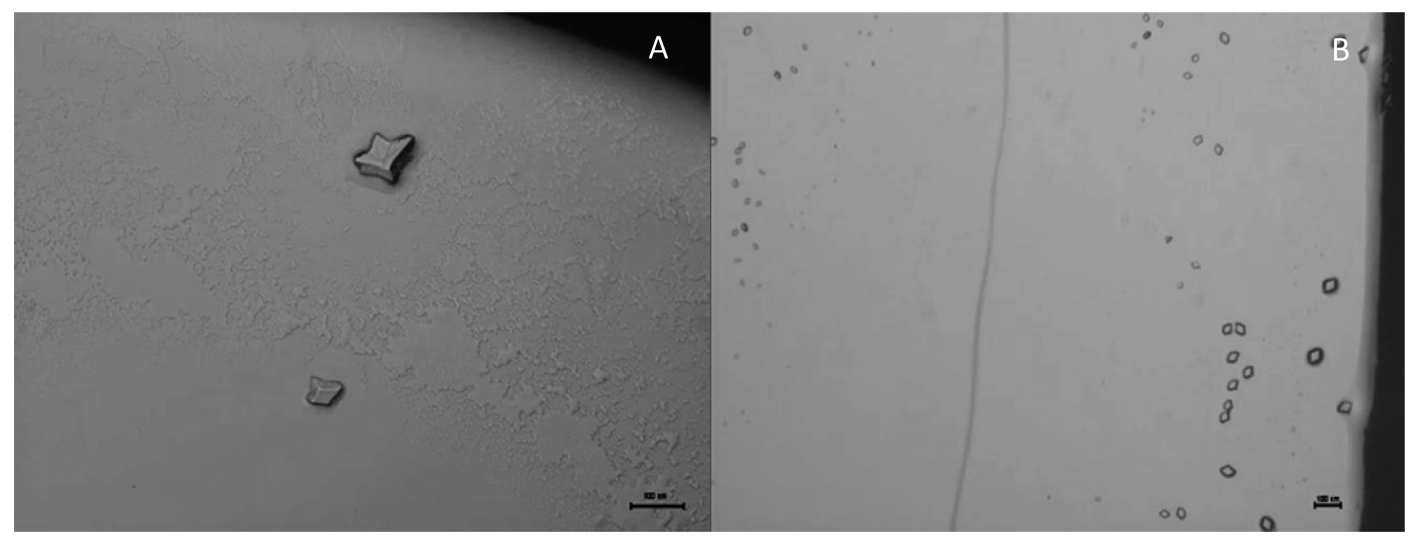

Figure 6. Optical microscopy images of insulin crystals on TCDB-functionalized surfaces with $20 \mathrm{~min}$. (A) and 60 min of evaporation (B). The scale bar indicates $100 \mu \mathrm{m}$ in both images. 
No significant differences were observed for BSA in terms of number of crystals, nucleation time, and crystal size on the various functionalized surfaces (Figure 9). However, the

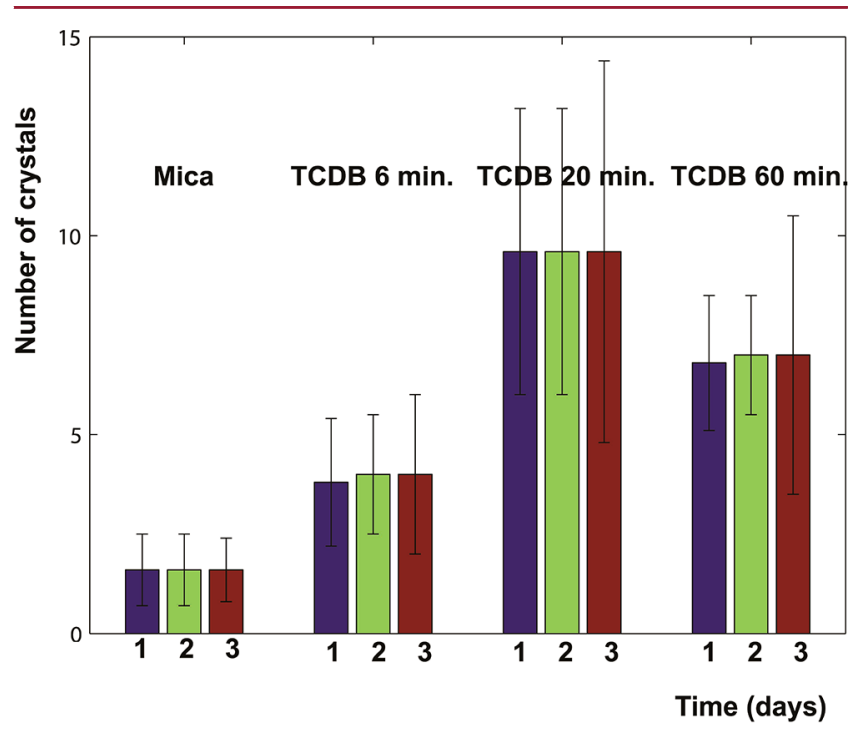

Figure 9. Number of bovine serum albumin crystals on (functionalized) muscovite mica. The nucleation rate is relatively fast, as no significant differences in the number of crystals are observed over time in the experiments with BSA.

number of crystals grown on the reference muscovite mica surface is significantly lower than on the TCDB functionalized surfaces. This indicates that BSA has a preference for the surfaces covered by TCDB in a similar way as is the case for talin. It is interesting to note that the solution containing BSA, as well as talin, has a $\mathrm{pH}$ close to 7 , which means that the carboxyl groups of TCDB are largely ionized, this in contrast to the cases involving insulin and HEWL.

The aim of exclusively investigating the effect of surface topography on protein crystallization behavior was hindered by the associated chemical change of the surfaces after more than $20 \mathrm{~min}$ of TCDB vapor deposition. Together, the protein crystallization experiments show that the surface topography and chemistry can have an effect on nucleation time, crystal size, and the number of crystals. It is also possible that the surface topography and chemistry do not affect the protein crystallization outcome, as was the case for the TCDB functionalized surfaces in combination with BSA and talin. Furthermore, there was no surface that gave optimal crystallization results for every investigated protein. Therefore, in a protein crystallization trial, templates with variable surface topography and chemistry should be used to find the optimal crystallization surface.

\section{CONCLUSION}

The crystallization of the various model proteins (BSA, HEWL, insulin, and talin) is influenced by the surface topography and chemistry of the vapor-deposited TCDB layers on muscovite mica. The effect of the various TCDB layers on nucleation density, nucleation rate, and crystal growth rate varies to a large extent for the different tested proteins. In a number of cases (BSA and insulin) the nucleation of protein crystals is enhanced on the TCDB-functionalized surfaces as compared to bare muscovite mica. An enhancement of protein nucleation on functionalized surfaces can be useful, as obtaining crystals from proteins for X-ray diffraction studies in life sciences is often impossible by a lack of nucleus formation.

\section{ASSOCIATED CONTENT}

\section{Supporting Information}

The Supporting Information is available free of charge on the ACS Publications website at DOI: 10.1021/acs.cgd.7b01174.

Synthesis of TCDB, and a detailed description of the protein crystallization conditions (PDF)

\section{AUTHOR INFORMATION}

\section{Corresponding Authors}

*E-mail: w.depoel@science.ru.nl.

*E-mail: j.munninghoff@science.ru.nl.

*E-mail: j.elemans@science.ru.nl.

*E-mail: w.vanenckevort@science.ru.nl.

*E-mail: a.rowan@science.ru.nl.

*E-mail: e.vlieg@science.ru.nl, Phone: +31243653070, Fax: +31243653067 .

ORCID 8

Wester de Poel: 0000-0002-4077-7231

Willem J. P. van Enckevort: 0000-0001-7436-8391

Elias Vlieg: 0000-0002-1343-4102

Notes

The authors declare no competing financial interest.

\section{ACKNOWLEDGMENTS}

We would posthumously like to acknowledge the work of Jan Smits, who performed X-ray diffraction to establish the crystal orientation of muscovite mica. AFM measurements were performed at NanoLab Nijmegen. Helene I.V. AmatdjaisGroenen is thanked for her elemental analysis of the synthesized compounds.

\section{REFERENCES}

(1) Blunt, M.; Lin, X.; Gimenez-Lopez, M. d. C.; Schröder, M.; Champness, N. R.; Beton, P. H. Directing two-dimensional molecular crystallization using guest templates. Chem. Commun. 2008, No. 20, 2304-2306.

(2) Singh, A.; Lee, I. S.; Kim, K.; Myerson, A. S. Crystal growth on self-assembled monolayers. CrystEngComm 2011, 13 (1), 24.

(3) Dressler, D. H.; Mastai, Y. Chiral crystallization of glutamic acid on self assembled films of cysteine. Chirality 2007, 19 (5), 358-365.

(4) Chen, J.; Myerson, A. S. Pasteur revisited: chiral separation by crystallization on self-assembled monolayers. CrystEngComm 2012, 14 (24), 8326-8329.

(5) Hiremath, R; Basile, J. A.; Varney, S. W.; Swift, J. A. Controlling molecular crystal polymorphism with self-assembled monolayer templates. J. Am. Chem. Soc. 2005, 127 (51), 18321-18327.

(6) Lee, A. Y.; Lee, I. S.; Dettet, S. S.; Boerner, J.; Myerson, A. S. Crystallization on confined engineered surfaces: A method to control crystal size and generate different polymorphs. J. Am. Chem. Soc. 2005, 127 (43), 14982-14983.

(7) Hiremath, R.; Varney, S. I.; Swift, J. A. Oriented crystal growth of 4-lodo-4'-nitrobiphenyl on polar self-assembled monolayer templates: A case for "Chemical epitaxy". Chem. Mater. 2004, 16 (24), 49484954.

(8) Travaille, A. M.; Kaptijn, L.; Verwer, P.; Hulsken, B.; Elemans, J.; Nolte, R. J. M.; van Kempen, H. Highly oriented self-assembled monolayers as templates for epitaxial calcite growth. J. Am. Chem. Soc. 2003, 125 (38), 11571-11577.

(9) Zhang, C. Y.; Shen, H. F.; Wang, Q. J.; Guo, Y. Z.; He, J.; Cao, H. L.; Liu, Y. M.; Shang, P.; Yin, D. C. An Investigation of the Effects of 
Self-Assembled Monolayers on Protein Crystallisation. Int. J. Mol. Sci. 2013, 14 (6), 12329-12345.

(10) Tsekova, D. S.; Williams, D. R.; Heng, J. Y. Y. Effect of surface chemistry of novel templates on crystallization of proteins. Chem. Eng. Sci. 2012, 77, 201-206.

(11) Pham, T.; Lai, D. T.; Ji, D.; Tuntiwechapikul, W.; Friedman, J. M.; Lee, T. R. Well-ordered self-assembled monolayer surfaces can be used to enhance the growth of protein crystals. Colloids Surf., B 2004, 34 (3), 191-196.

(12) Delmas, T.; Roberts, M. M.; Heng, J. Y. Y. Nucleation and Crystallization of Lysozyme: Role of Substrate Surface Chemistry and Topography. J. Adhes. Sci. Technol. 2011, 25 (4-5), 357-366.

(13) Falini, G.; Fermani, S.; Conforti, G.; Ripamonti, A. Protein crystallisation on chemically modified mica surfaces. Acta Crystallogr., Sect. D: Biol. Crystallogr. 2002, 58, 1649-1652.

(14) Fermani, S.; Falini, G.; Minnucci, M.; Ripamonti, A. Protein crystallization on polymeric film surfaces. J. Cryst. Growth 2001, 224 (3-4), 327-334.

(15) Tosi, G.; Fermani, S.; Falini, G.; Gallardo, J. A. G.; Ruiz, J. M. G. Crystallization of proteins on functionalized surfaces. Acta Crystallogr., Sect. D: Biol. Crystallogr. 2008, 64, 1054-1061.

(16) Liu, Y.-X.; Wang, X.-J.; Lu, J.; Ching, C.-B. Influence of the roughness, topography, and physicochemical properties of chemically modified surfaces on the heterogeneous nucleation of protein crystals. J. Phys. Chem. B 2007, 111 (50), 13971-13978.

(17) McPherson, A.; Shlichta, P. Heterogeneous and epitaxial nucleation of protein crystals on mineral surfaces. Science 1988, 239 (4838), 385-387.

(18) Sun, L. H.; Xu, C. Y.; Yu, F.; Tao, S. X.; Li, J.; Zhou, H.; Huang, S.; Tang, L.; Hu, J.; He, J. H. Epitaxial Growth of Trichosanthin Protein Crystals on Mica Surface. Cryst. Growth Des. 2010, 10 (6), 2766-2769.

(19) Bolanos-Garcia, V. M.; Chayen, N. E. New directions in conventional methods of protein crystallization. Prog. Biophys. Mol. Biol. 2009, 101 (1-3), 3-12.

(20) Saridakis, E.; Chayen, N. E. Towards a 'universal' nucleant for protein crystallization. Trends Biotechnol. 2009, 27 (2), 99-106.

(21) De Poel, W.; Pintea, S.; Drnec, J.; Carla, F.; Felici, R.; Mulder, P.; Elemans, J. A. A. W.; van Enckevort, W. J. P.; Rowan, A. E.; Vlieg, E. Muscovite Mica: Flatter than a Pancake. Surf. Sci. 2014, 619, 19-24.

(22) Carson, G.; Granick, S. Self-assembly of octadecyltrichlorosilane films on mica. J. Appl. Polym. Sci. 1989, 37 (9), 2767-2772.

(23) Carson, G. A.; Granick, S. Self-assembly of octadecyltrichlorosilane monolayers on mica. J. Mater. Res. 1990, 5 (8), 1745-1751.

(24) Kessel, C. R.; Granick, S. Formation and characterization of a highly ordered and well-anchored alkylsilane monolayer on micy by self-assembly. Langmuir 1991, 7 (3), 532-538.

(25) Kim, S.; Cho, K. W.; Curry, J. E. Measurements of the thickness compressibility of an n-octadecyltriethoxysilane monolayer selfassembled on mica. Langmuir 2005, 21 (18), 8290-8296.

(26) Malham, I. B.; Bureau, L. Growth and Stability of a SelfAssembled Monolayer on Plasma-Treated Mica. Langmuir 2009, 25 (10), 5631-5636.

(27) Woodward, J. T.; Ulman, A.; Schwartz, D. K. Self-assembled monolayer growth of octadecylphosphonic acid on mica. Langmuir 1996, 12 (15), 3626-3629.

(28) Benitez, J. J.; Ogletree, D. F.; Salmeron, M. Preparation and characterization of self-assembled multilayers of octadecylamine on mica from ethanol solutions. Langmuir 2003, 19 (8), 3276-3281.

(29) Bissel, P.; Onda, M.; Yoshihara, K.; Koyano, H.; Ariga, K.; Kunitake, T.; Oishi, Y.; Suehiro, K. Heptopus", a novel class of amphiphiles with seven alkyl chains. Synthesis and monolayer property. Langmuir 1999, 15 (5), 1791-1795.

(30) De Poel, W.; Pintea, S.; De Jong, A.; Drnec, J.; Carla, F.; Felici, R.; Op den Camp, H.; Elemans, J. A. A. W.; Van Enckevort, W. J. P.; Rowan, A. E.; Vlieg, E. Dibenzo crown ether layer formation on muscovite mica. Langmuir 2014, 30 (42), 12570-7.
(31) Kankate, L.; Balzer, F.; Niehus, H.; Rubahn, H. G. From clusters to fibers: Parameters for discontinuous para-hexaphenylene thin film growth. J. Chem. Phys. 2008, 128 (8), 084709.

(32) Andreev, A.; Matt, G.; Brabec, C. J.; Sitter, H.; Badt, D.; Seyringer, H.; Sariciftci, N. S. Highly anisotropically self-assembled structures of para-sexiphenyl grown by hot-wall epitaxy. Adv. Mater. 2000, 12 (9), 629.

(33) Lu, J.; Lei, S. B.; Zeng, Q. D.; Kang, S. Z.; Wang, C.; Wan, L. J.; Bai, C. L. Template-induced inclusion structures with copper(II) phthalocyanine and coronene as guests in two-dimensional hydrogenbonded host networks. J. Phys. Chem. B 2004, 108 (17), 5161-5165.

(34) Palermo, V.; Samori, P. Molecular self-assembly across multiple length scales. Angew. Chem., Int. Ed. 2007, 46 (24), 4428-4432. 